\title{
Coexisting Optic Disc Melanocytoma and Pituitary Adenoma
}

\author{
Yamini Attiku ${ }^{a}$ Pukhraj Rishia ${ }^{a}$ Shikha Bassi ${ }^{b}$ \\ ${ }^{a}$ Shri Bhagwan Mahavir Vitreoretinal Services, Sankara Nethralaya, Chennai, India; ${ }^{b}$ Department of \\ Neuro-Ophthalmology Services, Sankara Nethralaya, Chennai, India
}

\section{Established Facts}

- There is no known association of optic disc melanocytoma with pituitary tumors.

- Neuroimaging for optic disc melanocytoma is not a standard investigative procedure.

\section{Novel Insights}

- Optic disc melanocytoma can coexist with pituitary tumor.

- Disproportionate visual field defects associated with optic disc melanocytoma must trigger suspicion of a coexisting pathology causing visual field defect.

\section{Keywords}

Eye - Tumor - Optic disc melanocytoma - Pituitary adenoma $\cdot$ Hamartoma $\cdot$ Visual field

\begin{abstract}
Aim: To report a rare case of optic disc melanocytoma coexistent with pituitary adenoma. Methods: Ophthalmological examination with perimetry and magnetic resonance imaging (MRI) of the brain and orbits was done. Results: A 42-yearold woman presented with complaints of progressive diminution of vision in the right eye of 6 weeks' duration. Visual acuity in the affected right eye was $6 / 60$ and in the left eye it was $6 / 6$. On examination, a brown-black lesion was noted over the optic nerve head in the right eye. On perimetry, the visual field was constricted in the right eye and a superior altitudinal defect was found in the left eye. MRI of the brain and orbits revealed a pituitary adenoma with suprasellar ex-
\end{abstract}

\section{KARGER}

(c) 2019 S. Karger AG, Basel

E-Mail karger@karger.com

www.karger.com/oop tension. The patient underwent endoscopic transphenoidal pituitary adenoma excision with uneventful recovery. Three months following surgery, visual acuity improved to $6 / 6$ in both eyes with partial visual field recovery and was maintained at 10 months of follow-up. There was no recurrence or metastasis. Conclusion: A high degree of suspicion is required to screen for possible coexistent orbital or central nervous system pathology in cases of optic disc melanocytoma with disproportionate signs or symptoms.

(c) 2019 S. Karger AG, Basel

\section{Introduction}

Optic disc melanocytoma is a hamartoma [1]. It is usually asymptomatic and an incidental finding. Classically, it is a dark-brown or black lesion over the optic disc with peripapillary extension to the retina and choroid. It can 

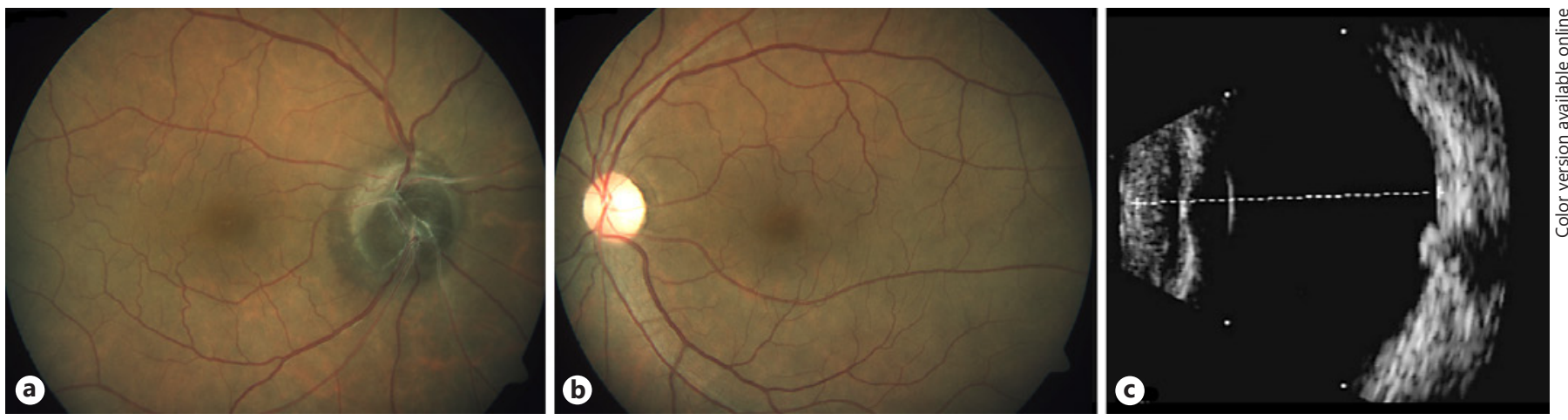

Fig. 1. At presentation. a Fundus photo of the right eye showing the optic disc melanocytoma. b Fundus photo of the left eye showing mild disc pallor. c Ultrasound B scan of the right eye showing the tumor with moderate surface reflectivity and homogenous internal reflectivity.

cause mild visual impairment in $25 \%$ of the cases. It is rare to find visual field constriction due to optic disc melanocytoma, unless there is a rapid growth with/without malignant transformation. Advanced visual field loss in an eye with optic disc melanocytoma can also occur with a coexisting central nervous system (CNS) tumor. A high degree of suspicion is required to screen for possible coexistent orbital or CNS pathology in such cases.

\section{Case Report}

A 42-year-old woman presented with complaints of progressive diminution of vision in the right eye of 6 weeks' duration. The patient had no relevant medical, surgical, or past ophthalmic history. There was no history of antecedent trauma or fever. A detailed ophthalmic examination was done. Best corrected visual acuity was $6 / 60$ in the right eye and 6/6 in the left eye. Intraocular pressure in both eyes was $10 \mathrm{~mm} \mathrm{Hg}$ each. Pupillary light reaction was sluggish in the right eye and brisk in the left. Anterior segment examination of both eyes was unremarkable. Ophthalmoscopic examination of the right eye revealed an elevated, brown lesion over the optic nerve head (Fig. 1a), measuring $2.2 \mathrm{~mm}$ (basal diameter) $\times 1.8 \mathrm{~mm}$ (height). There was no associated optic nerve edema, retinal hemorrhages, retinal edema, retinal exudates, subretinal fluid or vitreous seeding. There were no other lesions in the right eye. The left eye had mild temporal disc pallor (Fig. 1b). Color vision was reduced in the right eye and normal in the left eye. Ultrasound revealed a tumor over the optic nerve head with moderate surface reflectivity and homogenous internal reflectivity (Fig. 1c). Visual field examination showed constricted fields in the right eye and altitudinal field loss in the left eye (Fig. 2a, b). Considering the disproportionately advanced visual field loss in the right eye and the bilateral affliction of visual fields, magnetic resonance imaging (MRI) of the brain was done to rule out CNS pathology. MRI revealed a predominantly cystic pituitary tumor with suprasellar extension consistent with pituitary adenoma, and associated bleeding, and chiasmal compression (Fig. 3a). The patient was referred for neurosurgical opinion and underwent an endo- scopic transphenoidal pituitary tumor excision with uneventful recovery (Fig. 3b). Histopathologic evaluation revealed sheets of uniform polygonal cells traversed by delicate capillaries arranged in pseudorosettes and a papillary pattern. The cells had a moderate amount of eosinophilic cytoplasm and uniform, round nuclei with open chromatin. These findings were consistent with pituitary adenoma (Fig. 3c). Three months following surgery, visual acuity improved to $6 / 6$ in both eyes with significant bilateral visual field improvement (Fig. 2c, d).

\section{Discussion}

Optic disc melanocytoma is a dark-brown or black, benign lesion over the optic disc with peripapillary extension to the retina and choroid [2]. Histologically, it consists of tightly packed round-to-oval, heavily pigmented cells with copious quantities of cytoplasm and small, round, uniform, bland nuclei [2]. It can cause mild vision loss in $25 \%$ of cases with asymptomatic visual field defects in up to $90 \%$ of cases on the perimetry [3,4]. Causes for vision loss includes compression on the optic nerve, exudative retinal exudation, juxtapapillary choroidal neovascularization, tumor necrosis, central retinal vein obstruction, central retinal artery obstruction, and malignant transformation $[5,6]$. It is associated with ocular melanocytosis, which is present in up to $8 \%$ of cases [2]. Tumor growth has been reported in $10-15 \%$ of cases [7]. Malignant transformation occurs in 1-2\% of cases [2].

The most common visual field defect associated with optic disc melanocytoma is enlargement of the blind spot, which corresponds to the extension of the tumor beyond the margins of the optic disc. Other visual field defects noted include arcuate scotoma, paracentral scotoma, quadrantal defect, nasal step, and altitudinal field defect $[2,4$, 


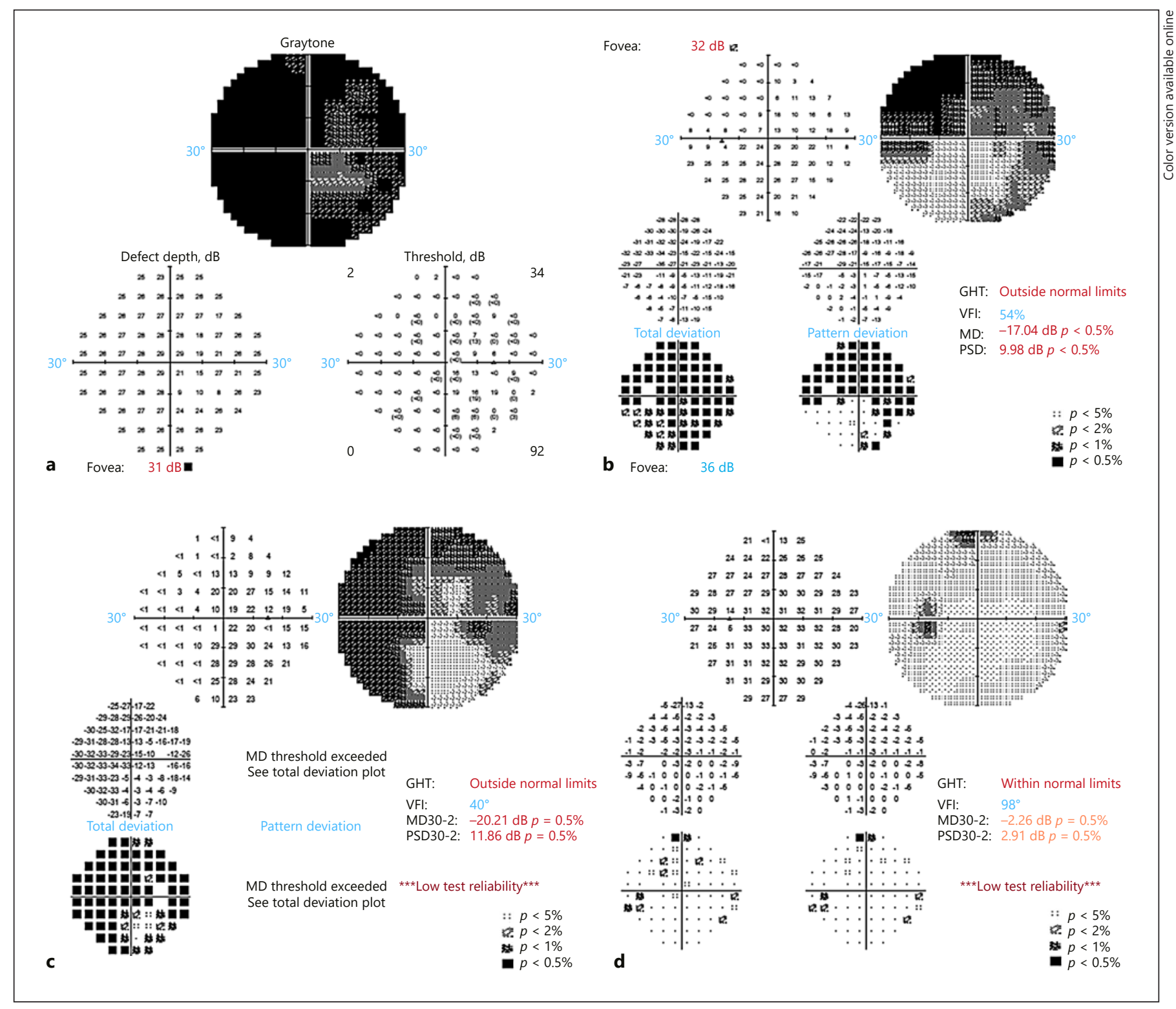

Fig. 2. a, b HVF (30-2) of the right and left eye at presentation. c, d At follow-up 3 months after surgery, HVF $(30-2)$ of the right and left eyes reveal improvement.

$5,8-10]$. These defects are the result of impairment of axonal flow due to compression on the nerve fiber bundles, or microcirculation, or due to ischemic optic neuropathy.

In our patient, visual fields of both eyes were affected which could not be attributed to the optic disc melanocytoma in one eye. This disparity required imaging of the cranium. There are other differential diagnoses that must be considered in such a situation. Choroidal melanoma with a secondary invasion of the optic nerve must be ruled out. Shinoda et al. [11] have reported a case of melanocy-

Optic Disc Melanocytoma and Pituitary Adenoma toma of the left optic nerve head and right retrobulbar optic neuropathy caused by compression by "tuberculum sellae meningioma." Walsh and Packer [12] have reported a case of bilateral melanocytoma of the optic disc associated with intracranial meningioma. A possible association between meningioma and optic disc melanocytoma is suspected due to the common embryonic origin from neural crest, rather than being an incidental co-occurrence.

In cases of optic disc melanocytoma with unexplained visual field changes, the clinician must also evaluate the 

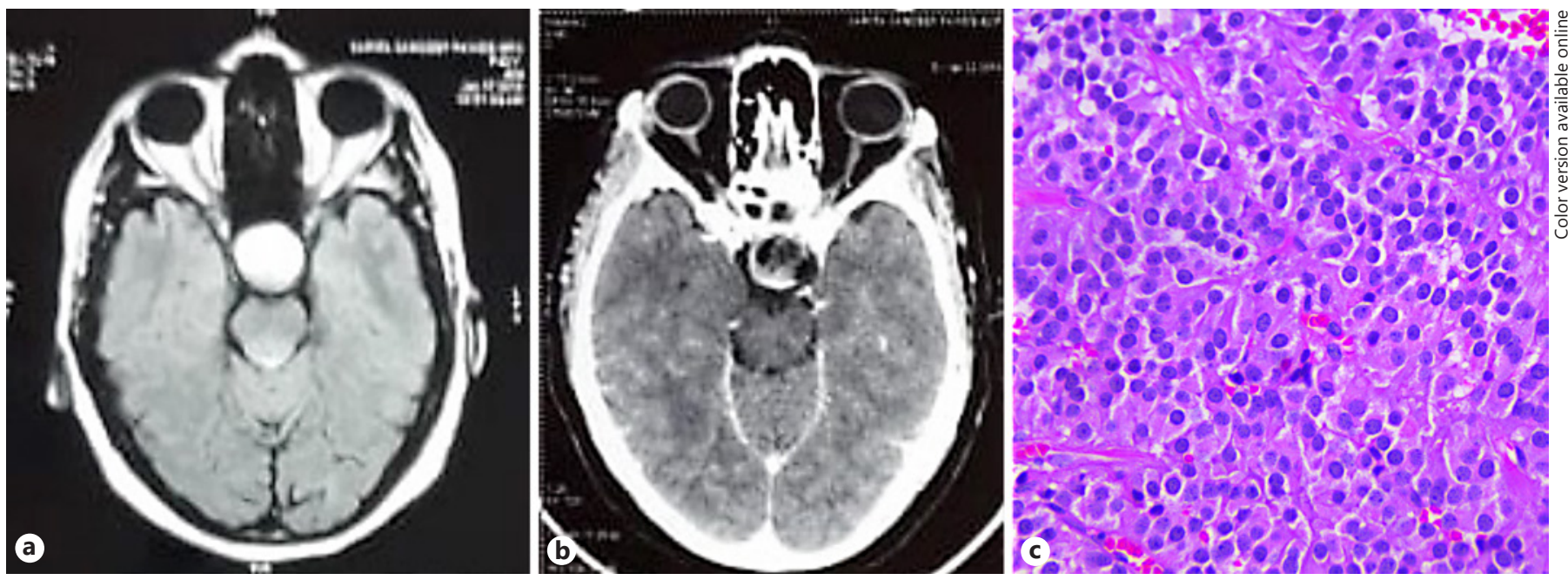

Fig. 3. a MRI image of the brain showing a well-circumscribed sellar mass. b MRI image of the brain post-surgery showing an empty sella. c Histopathology photomicrograph showing sheets of uniform polygonal cells arranged in pseudorosettes and papillary pattern $(\times 50, \mathrm{H} \& \mathrm{E})$.

patient for signs of "hypopituitarism," including fatigue, headache, diplopia, weight loss, cold/warm sensitivity, decreased appetite, facial puffiness, anemia, infertility, amenorrhea, and other signs. These findings can prompt the clinician to suspect a coexisting pituitary tumor.

In conclusion, this is a rare report of visual loss in a case of optic disc melanocytoma with unusual bilateral visual field defects, which on further investigation revealed an underlying pituitary adenoma that was successfully excised with resultant visual improvement.

\section{Statement of Ethics}

The authors have no ethical conflicts to disclose.

\section{Disclosure Statement}

The authors have no conflicts of interest to declare.

\section{Funding Sources}

There was no funding source involved.

\section{Author Contributions}

Dr. Yamini Attiku has been involved in the manuscript preparation, editing, and submission. Dr. Pukhraj Rishi has been involved in patient management, manuscript preparation, and editing. Dr. Shikha Bassi has been involved in patient management, and manuscript editing.

\section{References}

1 Zimmerman LE. Pigmented tumors of the optic nerve head The 22nd Annueal de Schweinitz Lecture. Am J Ophthalmol. 1960; 50:338.

2 Shields JA, Demirci H, Mashayekhi A, Shields CL. Melanocytoma of optic disc in 115 cases: the 2004 Samuel Johnson Memorial Lecture, part 1. Ophthalmology. 2004 Sep;111(9): 1739-46.

3 Archdale TW, Magnus DE. Melanocytoma of the optic disc. J Am Optom Assoc. 1993 Feb; 64(2):98-103.

4 Usui T, Shirakashi M, Kurosawa A, Abe H, Iwata K. Visual disturbance in patients with melanocytoma of the optic disk. Ophthalmologica. 1990;201(2):92-8.
5 Shields JA, Demirci H, Mashayekhi A, Eagle RC Jr, Shields CL. Melanocytoma of the optic disk: a review. Surv Ophthalmol. 2006 MarApr;51(2):93-104.

6 Rishi P, Venkatesh R. Central retinal artery occlusion secondary to optic disk melanocytoma. Retin Cases Brief Rep. 2012;6(2):212-5.

7 Joffe L, Shields JA, Osher RH, Gass JD. Clinical and follow-up studies of melanocytomas of the optic disc. Ophthalmology. 1979 Jun; 86(6):1067-83.

8 Say EA, Sinha N, Shields CL. Visual Field defects from Optic disk melanocitoma. Retina Today. 2010:32-4.

9 Osher RH, Shields JA, Layman PR. Pupillary and visual field evaluation in patients with melanocytoma of the optic disc. Arch Ophthalmol. 1979 Jun;97(6):1096-9.

10 Zografos L, Othenin-Girard CB, Desjardins L, Schalenbourg A, Chamot L, Uffer S. Melanocytomas of the optic disk. Am J Ophthalmol. 2004 Dec;138(6):964-9.

11 Shinoda K, Hayasaka S, Nagaki Y, Kadoi C, Kurimoto M, Okada E. Melanocytoma of the left optic nerve head and right retrobulbar optic neuropathy compressed by a tuberculum sellae meningioma. Ophthalmologica. 2000; 214(2):161-3.

12 Walsh TJ, Packer S. Bilateral melanocytoma of the optic nerve associated with intracranial meningioma. Ann Ophthalmol. 1971 Aug; $3(8): 885-8$ 